by changes that, so far, Spanish politicians have ignored or failed to tackle.

The creation of a ministry of science and innovation and the appointment of a respected scientist, Cristina Garmendia, to head it, give us hope for a change in direction.

Unless the necessary changes are implemented, the careers of Spanish scientists, particularly the younger ones, cannot flourish.

Rodrigo J. Carbajo ${ }^{\star}$, José Luis Neira†', Rosa Farràs*

*Laboratorio de Biología Estructural, Centro de Investigación Príncipe Felipe, Avenida Autopista del Saler 16, 46012 Valencia, Spain † Instituto de Biología Molecular y Celular, Edificio Torregaitán, Universidad Miguel Hernández, Avenida del Ferrocarril $s / n$, 03202 Elche, Alicante, Spain

西 (1)}

(

\section{Darwin-Wallace principle of natural selection}

SIR - In their Correspondence 'Celebrations for Darwin downplay Wallace's role' (Nature 451, 1050; 2008), G. W. Beccaloni and V. S. Smith question why Alfred Russel Wallace's achievements have been overshadowed by those of Charles Darwin, despite their discovery together of natural selection and its significance for the transformation of species (C. Darwin \& A. R. Wallace J. Proc. Linn. Soc. Lond. 3, 45-62; 1858). I think the reasons for this are threefold.

First, Darwin's 1859 book On the Origin of Species describes the theory of descent with i. belief in miracles and defended so-called supernatural phenomena, such as 'tabletapping, for the rest of his long life. This seriously undermined his credibility as a scientist, and cast a shadow over his brilliant theoretical work of 1858 on the struggle for existence in wild animal populations.

What can we do to rehabilitate Wallace and to acknowledge his important contributions to evolutionary biology? The 'DarwinWallace principle of natural selection' could be substituted for the old-fashioned 'darwinism', which smacks more of a political ideology than a modern scientific theory. This simple change in terminology might restore balance to the Darwin-dominated view of the history of the life sciences.

\section{U. Kutschera}

Institute of Biology, University of Kassel, Heinrich-Plett-Strasse 40,

D-34109 Kassel, Germany

\title{
Spain: leading role of scientists is heartening
}

SIR - In your Editorial 'A new Silver Age?' (Nature 451, 1029; 2008), you highlight the urgent need for reforms in the organization of science, after science funding in Spain has been increased during the past four years. The socialist government has since been re-elected. What changes is this likely to bring?

Scientific and academic interests will be served by the newly created ministry of science and innovation, headed by biologist Cristina Garmendia, who runs a biotechnology company. The new government's composition is heartening news for scientists - for example, the minister of health is a professor of physiology, the minister of industry is an economist with a strong interest in science, and even the minister of the interior is a professor of chemistry.

Leading up to the general election of 9 March, the socialist party held out the carrots of more funding and structural reforms for science. Implementation of their programme will modernize a system that stems from one designed by the first socialist government in 1982, which first introduced grants and evaluation procedures.

Thirty years ago, I wrote an article about science in newly democratic Spain (Nature 274, 8-9; 1978). The situation has changed radically since that time, and it promises to continue to do so under a forward-looking stewardship.

Pere Puigdomènech

Centre for Research in Agricultural Genomics, CSIC-IRTA-UAB, Jordi Girona 18,

08034 Barcelona, Spain

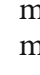
much more detail than is found in his short essay with Wallace, published the previous year. The book became a bestseller and was translated into many languages. Nature's archives reveal the immediate impact of Darwin's monograph - see, for instance, T. H. Huxley's anniversary Editorial ('The coming of age of The Origin of Species' Nature $22,1-4 ; 1880$ ), but this made no mention of Wallace's contribution.

Second, Wallace had always acknowledged the priority of Darwin with respect to their joint discovery published in 1858 . He used the term 'darwinism' as a synonym for 'the darwinian theory of natural selection' and popularized it (A. R. Wallace Darwinism Macmillan, London, 1889). To my knowledge, 'wallaceism' is a term that has never been coined.

Finally, Wallace was heavily involved with spiritualism by the 1860 s. He confirmed his

\section{The status of science in Muslim nations}

SIR - The decision made by the

Organization of the Islamic Conference, that only countries committed to donating funds will be allowed to join its standing committee on science and technology, is laudable and newsworthy. However, it hardly justifies the News in Brief headline 'Muslim nations raise status of science' (Nature 452, 517; 2008). A News Feature in the same issue reports the establishment of a research centre in Lisbon, made possible by the donation of half a billion euros (US\$782 million) by a single Portuguese philanthropist ('Navigating new waters' Nature 452, 528-529; 2008).

Nations are made up of individuals as well as governments. If governments in some Muslim states are not supporting science, why don't a few wealthy individuals step in? And if they did, would competent researchers, securely employed in a scientifically vigorous milieu, be willing to take up residence in the organization's member countries?

As your News Feature suggests, good scientists will go to Lisbon only if conditions are better than those elsewhere. The same applies even more forcefully to the Islamic countries, because conditions conducive to intellectual autonomy and scientific progress require more than a mere injection of capital. In Portugal, democracy needed to mature after the bloodless 'carnation revolution' in the 1970s ended a long spell of dictatorship. K. Razi Naqvi

Department of Physics,

Norwegian University of Science and Technology, N-7491 Trondheim, Norway 